\title{
DEPTH PROFILES OF NITROGEN AND CHLORINE IN PURE MATERIALS THROUGH AMS OF THE NEUTRON ACTIVATION PRODUCTS ${ }^{14} \mathrm{C}$ and ${ }^{36} \mathrm{Cl}$
}

\author{
DAVID ELMORE*, T Z HOSSAIN**, H E GOVE, T K HEMMICK \\ P W KUBIK, S JIANG ${ }^{\dagger}$, J P LAVINE** and S T LEE** \\ Nuclear Structure Research Laboratory, University of Rochester \\ Rochester, New York 14627
}

\begin{abstract}
Determination of the more common light elements such as nitrogen and chlorine at trace levels is difficult because of their high abundance on sample surfaces, in materials used to build analysis instruments, and in the residual gas of the instrument vacuum. We present here a new approach to analysis of these elements: accelerator mass spectrometry (AMS) combined with neutron activation. The problem of contamination is overcome by using neutron activation to produce long-lived radioisotopes which generally have low concentrations in the environment. For measurement of ${ }^{14} \mathrm{~N}$ and ${ }^{35} \mathrm{Cl}$, AMS can provide sensitive background-free measurements of their neutron activation products ${ }^{14} \mathrm{C}$ and ${ }^{36} \mathrm{Cl}$ and, in addition, can provide depth profiles. These are the first results of this new method: depth profiles of nitrogen and chlorine implanted in semiconductor grade silicon.
\end{abstract}

\section{INTRODUCTION}

Knowing the level and location (depth) of trace impurities becomes increasingly more important as semiconductor devices become smaller and attempts are made to reduce failure rates. In many cases, fabrication methods must be developed on a trial and error basis because some light impurities play a key role in changing electronic properties at levels not measurable with conventional techniques. Such effects can be assessed only by introducing known amounts of the impurity. It is difficult to reduce impurities arising from contamination without quantitative information on their concentrations as a function of depth. We show that the combination neutron activation/accelerator mass spectrometry (NA/AMS) allows us to measure nitrogen, chlorine, and probably several other elements with greater sensitivity than previously possible with other analysis techniques.

One of the important techniques for determining concentrations of trace elements near the surface of pure materials is secondary ion mass spectrometry (SIMS) (White \& Wood, 1986). Here, a positive oxygen ion beam of typically 3-20 keV sputters secondary ions from the surface which are then extracted through a potential of a few kilovolts and mass analyzed. The detection sensitivity for SIMS is limited by background produced by interaction of the primary beam with residual gases and by interference from molecules that cannot be mass-resolved while retaining high sensitivity.

The combination SIMS/AMS (Purser, Litherland \& Rucklidge, 1979) has been discussed (Casper, 1986) and applied to measurement of several trace elements in Si and GaAs (Anthony \& Thomas, 1983; Anthony \& Donahue, 1987) with a large improvement in sensitivity over SIMS alone. The AMS ion source focuses a positive cesium beam onto the sample

\footnotetext{
*Present address: Department of Physics, Purdue University, West Lafayette, IN 47907

**Analytical Technology Division, Research Laboratories, Bldg 82, Eastman Kodak Company, Rochester, New York 14650

†On leave from Institute of Atomic Energy, PO Box 275, Beijing, China
} 
material at a $45^{\circ}$ angle and negative ions are extracted at $90^{\circ}$. Improvements of up to two orders of magnitude over SIMS have been demonstrated for B, $\mathrm{P}, \mathrm{Ge}, \mathrm{Sb}$, and $\mathrm{Au}$ in Si or GaAs (Anthony \& Donahue, 1987). The limitation of SIMS/AMS does not result from a low overall efficiency nor from interference from other ion species, but rather from contamination of the element being measured in the cesium, in the materials of the ion source, and in the residual gas.

The problem of contamination is largely circumvented with neutron activation analysis (NAA). In NAA, the sample is introduced into the high neutron flux of a reactor. Here, an isotope of the element of interest is transformed by a nuclear reaction into a radioactive isotope of the same or a different element. The concentration of the original element is determined from the known cross-section for this reaction, the neutron flux and the counting rate for the decay of the radioisotope. Except for recoil effects, the radioisotope is produced in situ so that contamination of the element of interest by any gases in contact with the sample during irradiation are small except on the surface. Background levels of the radioisotope present before irradiation (eg, produced from cosmic rays) are many orders of magnitude lower than those produced artificially. As a result, high sensitivities can be achieved for many elements. NAA is applicable primarily to bulk analyses, but most work with semiconductors requires detailed depth profiles. Federoff $e$ t al (1987) have measured bulk nitrogen by NAA, which requires decay counting of the long-lived radioisotope ${ }^{14} \mathrm{C}$.

The NAA/SIMS/AMS combination (which we shorten to NA/AMS) has many of the advantages and overcomes many of the limitations of the individual analysis methods of NAA, SIMS, and AMS. With NA/AMS, a long-lived radioisotope is produced by neutron activation and then, after a cooling time sufficient to permit handling, the sample is placed directly in the ion source of an AMS system. Depth profiles of the radioisotope are determined with resolutions comparable to SIMS. The problem of contamination is solved as with NAA, since the natural levels of radioisotopes in the ion source are very low, but NA/AMS has the added benefit that the depth profile identifies any contamination on the surface at the time of irradiation. As with SIMS, the absolute concentration can be obtained by normalization to a standard prepared by implantation into the same matrix.

\section{MATERIALS AND METHODS}

The samples we used to demonstrate the performance and utility of NA/AMS for analysis of nitrogen and chlorine were wafers $500 \mu \mathrm{m}$ thick cut from a single-crystal silicon boule. They were coated with a $0.06 \mu \mathrm{m} \mathrm{SiO}_{2}$ layer to reduce channeling effects during implantation. (The amorphous layer produces random small-angle scattering which eliminates the possibility that the implantation beam will align with a crystal axis and penetrate further into the crystal by channeling.) They were implanted with $200 \mathrm{keV}$ nitrogen $\left(10^{16}\right.$ atoms $\left.\mathrm{cm}^{-2}\right)$ and $200 \mathrm{keV}$ chlorine $\left(10^{14}\right.$ atoms $\left.\mathrm{cm}^{-2}\right)$ at IICO, Santa Clara, California. Samples were irradiated with thermal neutrons at the University of Buffalo reactor facility, Buffalo, New York. Doses were 5 $\mathrm{hr}$ (nitrogen sample) and $50 \mathrm{hr}$ (chlorine sample) at $3 \times 10^{13}$ neutrons $\mathrm{cm}^{-2} \mathrm{~s}^{-1}$. The oxide layer was removed prior to AMS by etching with HF. 
We made the AMS measurements using the University of Rochester MP-tandem accelerator facility (Kubik et al, 1987) using techniques developed for ${ }^{14} \mathrm{C}$ (Bennett et al, 1978) and ${ }^{36} \mathrm{Cl}$ (Elmore et al, 1979). We used the scanning HICONEX cesium sputter negative ion source (Genus Inc, Newburyport, Massachusetts). The same model was used for SIMS/ AMS measurements at the University of Arizona (Anthony \& Donahue, 1987) and is described in Elmore and Philips (1987). We modified it for raster scanning by restricting the cesium beam with an aperture placed $8.5 \mathrm{~cm}$ in front of the ionizer. The cesium spot, focused to a diameter of $<0.5 \mathrm{~mm}$, was rastered over $2 \mathrm{~mm}^{2}$ by adding to the focusing potentials of the split Einzel lens, a triangle wave (X direction) and sawtooth wave (Y direction) produced by fast power supplies (Kepco Inc, Flushing, New York). The frame period (time to cover the region once) was 1.6 seconds and the computer accepted the central region, ca $0.5 \mathrm{~mm}^{2}$.

\section{RESULTS AND DISCUSSION}

The results for depth profiles of three samples are shown in Figure 1. Figure $1 \mathrm{~A} \& \mathrm{~B}$ show profiles of ${ }^{14} \mathrm{C}$ in the irradiated samples. A rather large background is seen in the irradiated blank. The nitrogen implant peak is seen above the background in Figure $1 \mathrm{~B}$ at ca 5 minutes into the scan. We did not understand the background until we received results of a SIMS measurement from Charles Evans Associates, Redwood City, California: a scan of $\mathrm{SiN}^{-}$in a sample from the same wafer showed a nice clean implant peak without substantial background. We then realized that the surface background must be coming from activation of nitrogen in the air above the samples during irradiation. We had not thought that this air would be a problem since the surface oxide layer was removed prior to the AMS measurement. However, the ${ }^{14} \mathrm{C}$ recoils following the ${ }^{14} \mathrm{~N}(\mathrm{n}, \mathrm{p})$ reaction with an energy of $42 \mathrm{keV}$ and gets implanted into the silicon. The long exponential decrease into the Si probably is a result of some small fraction of the recoil ${ }^{14} \mathrm{C}$ channeling into the crystal. For future irradiations we plan to place the samples in a vacuum or argon gas. This should eliminate the background problem; however, the ${ }^{14} \mathrm{C}$ recoil will always tend to smooth out any sharp features in nitrogen profiles.

Figure $1 \mathrm{C}$ shows a profile of ${ }^{36} \mathrm{Cl}$ for a sample implanted with chlorine and irradiated in a reactor. The ${ }^{36} \mathrm{Cl}$ is produced from the ${ }^{35} \mathrm{Cl}(\mathrm{n}, \gamma)$ reaction and thus represents the concentration of chlorine. In contrast to the ${ }^{14} \mathrm{C}$ scans, there is little background as expected, since there was little chlorine above the sample during irradiation and the recoil energy of the ${ }^{36} \mathrm{Cl}$ is only $4 \mathrm{eV}$. The scan of ${ }^{36} \mathrm{Cl}$ on the irradiated blank (not shown) produced ca 20 counts in the first few seconds, then a background counting rate of $<1$ count per minute.

From Figure 1, the dynamic range of the method is ca $10^{5}$, a typical performance for SIMS. This shows a good supression of the ions that are sputtered from the edge of the pit, redeposited in the center region, and accepted by the computer. In our scans the counting rate decreased to ca 1 $\mathrm{cpm}$ for both the nitrogen and chlorine implant samples. If we had not had such high peak values this minimum counting rate would probably have 


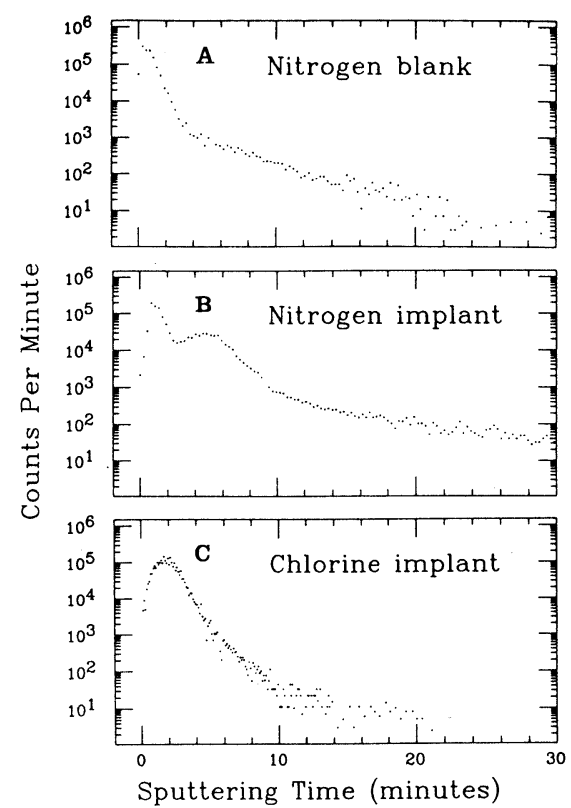

Fig 1.Depth profiles of ${ }^{14} \mathrm{C}(\mathrm{A}, \mathrm{B})$ and ${ }^{36} \mathrm{Cl}(\mathrm{C})$ in single-crystal silicon wafers that were implanted with $10^{16}$ at $\mathrm{cm}^{-2}$ of nitrogen $(\mathrm{B})$ and $10^{14}$ at $\mathrm{cm}^{-2}$ chlorine $(\mathrm{C})$ and then irradiated in a reactor. The sputtering rate, determined by later measurement of the hole depth was $0.08 \mu \mathrm{m} / \mathrm{min}$ and each scan of the cesium beam took 16 seconds to cover $2 \mathrm{~mm}^{2}$. Nitrogen and chlorine concentrations are proportional to the measured ${ }^{14} \mathrm{C}$ and ${ }^{36} \mathrm{Cl}$ concentrations produced by neutron activation. Since counting rates above ca $10^{4} \mathrm{cpm}$ saturated the computer, we inserted a $33 \%$ transmission mesh attenuator at the beginning of each scan and then removed it after the counting rate became low enough. The data plotted have been corrected for this attenuation.

been lower. In any event, $1 \mathrm{cpm}$ represents a practical limit for obtaining quantitative information on the impurity content, so we will use that value below for quoting the sensitivity.

For the nitrogen implant $\left(10^{16}\right.$ atoms $\left.\mathrm{cm}^{-2}\right), 3.8 \times 10^{4}$ events were counted under the peak after subtracting background. The sputtering rate was $0.08 \mu \mathrm{m} / \mathrm{min}$. From this information we compute that $1 \mathrm{cpm}$ corresponds to $3.3 \times 10^{16}$ nitrogen atoms per $\mathrm{cm}^{3}$. This sensitivity does not yet represent an improvement over other techniques but we expect to be able to improve it by about two orders of magnitude by increasing the neutron dose to $100 \mathrm{hr}$ at $10^{14} \mathrm{~cm}^{-2} \mathrm{sec}^{-1}$, a dose that is not too difficult to obtain at existing reactors. A sensitivity of $5 \times 10^{14}$ at $\mathrm{cm}^{-3}(4 \mathrm{ng} / \mathrm{g})$ would surpass the best obtained with SIMS of SiN- in silicon (Hockett, Evans \& Chu, 1988). This SIMS measurement is only possible in a silicon matrix. Our NA/AMS measurement would be possible in matrices that do not have long-lived activation products such as GaAs.

For the chlorine implant $\left(10^{14}\right.$ atoms $\left.\mathrm{cm}^{-2}\right), 2.4 \times 10^{5}$ events were collected under the peak. From this we compute that $1 \mathrm{cpm}$ corresponds to $7 \times 10^{13}$ chlorine at $\mathrm{cm}^{-3}$. The sensitivity for a neutron dose of $100 \mathrm{hr}$ at $10^{14}$ $\mathrm{cm}^{-2} \mathrm{sec}^{-1}$ would be $1 \times 10^{13}$ at $\mathrm{cm}^{-3}$ or $0.3 \mathrm{ng} / \mathrm{g}$. 
We measured the efficiency of the accelerator using the stable isotope beams ${ }^{12} \mathrm{C}$ and ${ }^{37} \mathrm{Cl}$ produced from graphite and $\mathrm{AgCl}$ to be $25 \%$ and $10 \%$. From the known implant dose, neutron dose, and production cross-section, the areal density of ${ }^{14} \mathrm{C}$ and ${ }^{36} \mathrm{Cl}$ are computed to be $1 \times 10^{10}$ and $2.3 \times 10^{10}$ at $\mathrm{cm}^{-2}$. The area of the sample from which negative ions are accepted is estimated to be ca $0.5 \mathrm{~mm}^{2}$. From this the ion source efficiency is found to be $0.3 \%$ for carbon and $2 \%$ for chlorine. This can be compared to efficiencies in graphite and $\mathrm{AgCl}$ of ca $3 \%$ and $5 \%$ (Elmore \& Phillips, 1987). The efficiency of forming negative ions in the ion source is dependent on the sample matrix and is expected to be less in silicon. The efficiency is reduced least for chlorine because its electron affinity is higher than that of silicon.

In some cases, activation of other elements produce a background that cannot be distinguished from the element of interest. For example, ${ }^{14} \mathrm{C}$ is produced by the ${ }^{17} \mathrm{O}(\mathrm{n}, \alpha)$ reaction, a limitation for measuring nitrogen in a $\mathrm{SiO}_{2}$ matrix. The production of ${ }^{14} \mathrm{C}$ from oxygen is a factor of $5 \times 10^{-5}$ times lower than the ${ }^{14} \mathrm{~N}(\mathrm{n}, \mathrm{p})$ reaction, because of the low abundance of ${ }^{17} \mathrm{O}$ and a lower cross-section. However, because oxygen is a major component of $\mathrm{SiO}_{2}$, the amount of ${ }^{14} \mathrm{C}$ produced from this is high, equivalent to that produced from a nitrogen concentration of $3 \times 10^{18}$ atoms $\mathrm{cm}^{-3}$. Therefore, oxygen containing materials are not suitable for measuring low-level nitrogen.

\section{CONCLUSION}

It is 11 years since AMS was first applied to ${ }^{14} \mathrm{C}$ detection and ca 40 years since the first reactors made neutron activation analysis possible. We have described a new technique that uses a combination of these two methods to measure trace levels of light elements. The performance for nitrogen and chlorine in silicon exceeds that possible with conventional techniques. NA/AMS is possible for other light elements including beryllium, carbon, calcium, iron, cobalt, and nickel and in other matrices including GaAs. NA/AMS can measure depth profiles not possible with NAA alone. AMS completely removes interference from molecules and, in many cases, isobars. Contamination from residual gas, which adversely affects AMS and SIMS measurements of trace elements, has been dealt with by the use of NAA. Although we have combined two techniques that each require rather specialized equipment, we do not feel that access to reactors and accelerators will be too limited to allow widespread use of NA/AMS for research purposes. The world now has more than 25 AMS facilities (Woelfli, 1987) and more than 100 research reactors at universities and major laboratories. The artificial levels produced in these measurements are generally higher than those found in natural samples, therefore care must be taken not to contaminate ion sources that are also used for measurement of low-level natural samples. 


\section{ACKNOWLEDGMENTS}

We gratefully acknowledge the help of P Sharma, R Teng, W Hood, and members of the NSRL operations crew in carrying out the measurements. We also acknowledge fruitful discussions with U Fehn, W Kutschera and W Lanford. The work at NSRL was supported by Eastman Kodak Company and National Science Foundation grant PHY-8515908.

\section{REFERENCES}

Anthony, J M and Donahue, D J, 1987, Accelerator mass spectrometry solutions to semiconductor problems: Nuclear Instruments \& Methods, v B29, p 77-82.

Anthony, J M and Thomas, J, 1983, Accelerator based mass spectrometry of semiconductor material: Nuclear Instruments \& Methods, v 218, p 463.

Bennett, C L, Beukens, R P, Clover, M R, Elmore, D, Gove, H E, Kilius, L, Litherland, A $\mathrm{E}$ and Purser, K H, 1978, Radiocarbon dating with electrostatic accelerators: Dating of milligram samples: Science, v 201, p 345-347.

Casper, L A, 1986, Characterization of materials and processes for semiconductor devices, in Elmore, D, ed, Interagency briefing and workshop to explore needs and opportunities for AMS applications, Proc, Washington, DC, March 28-29, 1985: Univ Rochester, Rochester, New York, p 36-42.

Elmore, D, Fulton, B R, Clover, M R, Marsden, J R, Gove, H E, Naylor, H, Purser, K H, Kilius, L R, Beukens, R P and Litherland, A E, 1979, Analysis of ${ }^{36} \mathrm{Cl}$ in environmental water samples using an electrostatic accelerator: Nature, v 277, p 22-25.

Elmore, D and Phillips, F M, 1987, Accelerator mass spectrometry for measurement of longlived radioisotopes: Science, v 236, p 543-550.

Fedoroff, M, Samosyuk, V N, Rouchaud, J C and Loos-Neskovic, C, 1987, Determination of nitrogen in solids by photon and reactor neutron activation: Jour Radioanal Nuclear Chem, v 112, p 319-325.

Hockett, R S, Evans, C A, Jr and Chu, P K, 1988, The SIMS measurement of nitrogen in nitrogen-doped CZ-silicon: SIMS VI Conf Proc, Versailles, France.

Kubik, P K, Elmore, D, Hemmick, T K, Gove, H E, Fehn, U, Teng, R T D, Jiang, S and Tullai, S, 1987, Accelerator mass spectrometry at the University of Rochester: Nuclear Instruments \& Methods, v B29, p 138-142.

Purser, K H, Litherland, A E and Rucklidge, J C, 1979, Secondary ion mass spectrometry at close to single-atom concentration using DC accelerators: Surface \& Interface Analysis, v $1, \mathrm{p} 12$.

White, F A and Wood, G M, 1986, Mass spectrometry: Applications in science and engineering: New York, Wiley-Interscience.

Woelfli, W, 1987, Advances in AMS: Nuclear Instruments \& Methods, v B29, p 1-13. 